\title{
Analysis of Triquetral-Lunate Fusion
}

\author{
STANLEY M. GARN, A. ROBERTO FRISANCHO, ANDREW K. \\ POZNANSKI, JUDY SCHWEITZER AND MARY B. MCCANN \\ Center for Human Growth and Development and Department of Radiology, \\ University of Michigan, Ann Arbor, Michigan 48104 and Nutrition \\ Program, Center for Disease Control, Rockville, Maryland 20852
}

\begin{abstract}
Fusion of the centers of the triquetral and lunate (the os lunatotriquetrum ) was observed in $1.6 \%$ of 7,543 subjects primarily of African origin as compared with $0.1 \%$ of 11,663 persons of European origin. The fusion was twice as common in females as in males, multifactorial inheritance was suggested in the lineages studied, and a possible selective disadvantage was postulated after comparison with West African fusion frequencies.
\end{abstract}

Although any pair of adjacent carpal centers may exhibit fusions (O'Rahilly, '53, 57), those on the ulnar side and the same row are most commonly involved. The capitate and the hamate are the most frequently fused carpal centers of the distal row and those of the os triquetrum and os lunatum in the proximal row. Triquetrallunate fusion, moreover, exhibits notable geographical diversity, with a frequency well under $1 \%$ in Europeans, 1-2\% in East Africans and a reported maximum of $8-9 \%$ in the Hausa of Nigeria (Smitham, '48; MacKay, '52; Silverman, '55; Cockshott, '63).

In the course of the recent Ten-State Nutrition Survey of the United States, we have been able to provide new estimates of the frequency of triquetral-lunate fusion in an unusually large sample of non-hospitalized volunteers, exceeding in number all previous survey data combined. Starting with 26,304 postero-anterior handwrist radiographs of subjects of known age, sex and origin, we have narrowed the sample to 21,715 subjects in whom the radiographic images provided sufficient indication of lunate and triquetral development to make the diagnosis of fusion certain. Subjects with rheumatoid arthritis, arthrogryposis and other anomalies ordinarily associated with fusion were excluded.

As shown in the table, triquetral-lunate carpal fusion (the os lunatotriquetrum) is extremely rare in subjects of European ancestry, probably no more frequent than one per thousand, in our combined-sex tabulations. The frequency of fusion of these two bones appears to be of a comparable order for American Indians (primarily Navajos) and Mexican-Americans ("Chicanos") studied. However, in participants indicated in the category "Black" (American Negroes, American Colored), the frequency is nearly 16 per thousand. For combined-sex tabulations, the frequency of triquetral-lunate fusion is 1.0 per thousand in 11,663 subjects of European ancestry and 15.8 per thousand in 7,543 subjects primarily of African ancestry.

In all groups considered here, triquetrallunate fusion was more frequent in females than males, both in children and adults, hence not an artifactual product of the developmental advancement of the female hand skeleton. Overall, the comparative frequencies were nearly a perfect $2: 1$ ratio, i.e., $0.80 \%$ in females and $0.38 \%$ in males, significantly different from a $1: 1$ ratio by any reasonable test of significance. Of the 133 triquetral-lunate fusions observed, 86 were registered in the Black females alone.

Since the Ten-State Nutrition Survey emphasized family-line participation, whenever possible, the extent of parent-child and sibling concordance with respect to the os lunatotriquetrum could be determined. In 42 parents of affected subjects, the trait was observed in 5\%. Among 65 children of adult propositi, triquetral-lunate fusion was present in $3 \%$. Among 177 siblings of index cases, using only one such index case per lineage, the frequency of fusion 
was again $5 \%$. From these lineage data it is clear that the trait is familial. However, allowing for a high rate of illegitimacy, it does not correspond to models of simple recessive or simple dominant inheritance. Moreover, simple X-linkage may be excluded from consideration because of male-to-male transmission, from the fact that the proportion of affected sisters among the siblings of male propositi did not exceed the proportion of affected brothers of female propositi (@6\% in each event) and both equaled the proportion of affected sisters of female propositi ( 3 out of 51). The mode of inheritance for this fusion would appear to be multifactorial with a major influence of sex in its expression.

With 133 cases of the triquetral-lunate fusion, it was possible to test possible associations discussed by previous authors. We can therefore agree with Silverman ('55) that the development of the fusions is not associated with accessory centers. However, we cannot agree with Hughes and Tanner ('66) who associate this fusion with other carpal or metacarpal abnormalities. Though the fusion in question may be associated with metacarpal and phalangeal reductions in pseudohypoparathyroidism or symphalangism, for example, no such relationships were observed in the present sample. Indeed, there was a lack of association with (1) brachymesophalangia, (2) clinodactyly, (3) cone-epiphyses, (4) metacarpal reductions, (5) phalangeal reductions, (6) pseudo-epiphyses, (7) medullary stenosis, (8) polydactyly and (9) thumb abnormalities in general. Review of the medical histories of the propositi provided no indication of statural reduction, cardiac disease or metacarpal and phalangeal elongations as in the Holt-Oram syndrome.

Triquetral-lunate fusion here emerges as an African marker, 16 times more frequent in American "Black" subjects with 70-85\% African genes (cf. Reed, '69). The observed frequency in American Negroes (16 per thousand) though high, is still so much lower than has been reported for Ibo, Hausa, and Yoruba (who contributed greatly to the ancestry of the American Negro, cf. Reed, '69) as to suggest a possible selective disadvantage
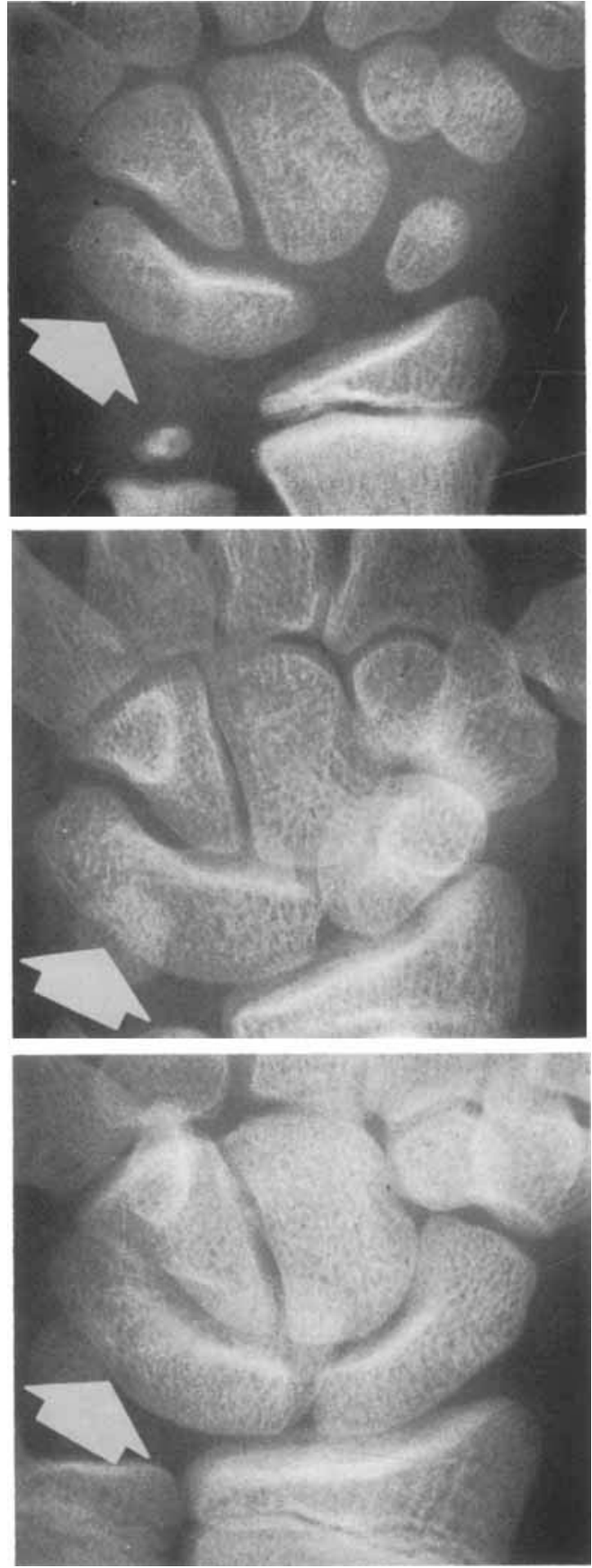

Fig. 1 Three siblings aged 9, 13 and 16 with the os lunatotriquetrum from a family of six from South Carolina. The developmental sequence shown above includes the pisiform in the older siblings (middle and bottom) and the elongation of the scaphoid in the 16 year old male (bottom). 
TABLE 1

Frequency (in per cent) of the triquetral-lunate fusion in different populations and in males and females

\begin{tabular}{|c|c|c|c|c|c|c|}
\hline \multirow{2}{*}{ Group } & \multicolumn{3}{|c|}{ Males } & \multicolumn{3}{|c|}{ Females } \\
\hline & Observed 1 & Affected & Frequency & Observed: & Affected & Frequency \\
\hline American Indian & 307 & 0 & 0.00 & 311 & 0 & 0.00 \\
\hline Mexican Americans & 636 & 0 & 0.00 & 953 & 1 & 0.10 \\
\hline Whites & 5356 & 4 & 0.07 & 6307 & 8 & 0.13 \\
\hline Puerto Ricans & 173 & 0 & 0.00 & 129 & 1 & 0.78 \\
\hline Blacks & 3207 & 33 & 1.03 & 4336 & 86 & 1.98 \\
\hline Totals & 9679 & 37 & 0.38 & 12036 & 96 & 0.80 \\
\hline
\end{tabular}

1 Subjects aged 3.0 years and older.

for the trait outside of Africa. The marked sex difference and the $2: 1$ ratio of affected females to affected males is an apparently new finding, and one that cannot be due to sampling considerations alone. The $2: 1 \mathrm{fe}$ male to male ratio differs from the $1: 1 \mathrm{fe}$ male to male ratio for capitate-hamate fusion seen in the same groups studied. The os lunatotriquetrum is five to seven times more often observed within lineages than chance alone would suggest, but the apparent mode of inheritance does not fit simple Mendelian models. Fusion of the os triquetrum and the os lunatum is not associated with other fusions, other carpal-metacarpal phalangeal abnormalities nor size reductions, though such associations may be observed in other single-gene substitutions, chromosomal abnormalities and in dysmorphogenesis.

\section{ACKNOWLEDGMENTS}

This study was supported by Contract HSM 110-69-22 with the Nutrition Program, Center for Disease Control, Health
Services and Mental Health Administration. All data analyses were completed by Jerrold M. Nagy and the manuscript was completed by Shirley M. Garrett.

\section{LITERATURE CITED}

Cockshott, P. 1963 Carpal fusions. Am. J. Roent., 89: 1260-1271.

Hughes, P. C. R., and J. M. Tanner 1966 The development of carpal bone fusion as seen in serial radiographs. Brit. J. Radiol., 39: 943949.

MacKay, D. H. 1952 Skeletal maturation in the hand: a study of development in East African children. Trans. Roy. Soc. Trop. Med. Hyg., 46: 135-150.

O'Rahilly, R. 1953 A survey of carpal and tarsal anomalies. J. Bone Joint Sur., 35-A: 626642 .

1957 Developmental deviations in the carpus and the tarsus. Clin. Ortho., 10: $9-18$.

Reed, T. E. 1969 Caucasian genes in American Negroes. Science, 165: 762-768.

Silverman, F. N. 1955 A note on the os lunatotriquetrum. Am. J. Phys. Anthrop., 13: 143145.

Smitham, J. H. 1948 Some observations on certain congenital abnormalities of the hand in African natives. Brit. J. Radiol., 21: 513-518. 